\title{
Scaling Relationship between the Number of Aftershocks and the Size of the Main Shock
}

\author{
Yoshiko Yamanaka* and Kunihiko Shimazaki \\ Earthquake Research Institute, The University of Tokyo, \\ Bunkyo-ku, Tokyo 113, Japan
}

The logarithmic number of aftershocks which occur within one month after a large shallow earthquake in Japan is found to be proportional to the logarithm of the seismic moment of the main shock. The proportional constants for interplate and intraplate earthquakes are different, but it turns out to reflect a similar difference in scaling relations of the fault area to the seismic moment between interplate and intraplate earthquakes. Thus we can derive the fundamental relationship that the aftershock number is proportional to the fault area of the main shock. This is consistent with the hypothesis that aftershocks are generated by unbroken strong patches on the main-shock fault, if the patch density is constant. Combining this new result with the results of previous studies on aftershocks, we propose that a rate of aftershock occurrence is given by

$$
n(t) \mathrm{d} t=\frac{k S 10^{-b M_{\mathrm{th}}}}{(t+c)^{p}} \mathrm{~d} t,
$$

where $n(t)$ indicates the number of aftershocks which occur $t$ days after the main shock, $S$ indicates the fault area of the main shock in $\mathrm{km}^{2}, M_{\mathrm{th}}$ is the threshold magnitude, $b$ is the $b$-value of the Gutenberg-Richter relationship, and $c$ and $p$ are the $c$-and $p$-values, respectively, of the modified Omori formula. The constant $k$ amounts to 13.4 for an interplate earthquake and to 31.7-63.5 for an intraplate earthquake depending on the assumption on its fault width. Apparently the areal density of aftershocks on the fault plane is higher for an intraplate earthquake than for an interplate earthquake. Further examination of the results suggests that the areal density of the aftershocks of a continental intraplate earthquake may be systematically higher than that of an oceanic intraplate earthquake. These differences may indicate some intrinsic difference in rupturing process among a continental intraplate, an oceanic intraplate, and an interplate events.

\section{Introduction}

It is a general rule that a large shallow earthquake is followed by many aftershocks, but exceptions certainly exist. Since the detection ability of observation system has recently improved, occurrence of a large event with few, if any, aftershocks should be

Received July 5, 1990; Accepted October 2, 1990

* To whom correspondence should be addressed. 
related with some peculiar feature of the source process or the state of the crust near the source.

As a first step towards better understanding what controls the number of aftershocks, we investigate in this study the relationship between the number of aftershocks and the fault parameters of the main shock. It will be shown that the aftershock number is proportional to the fault area of the main shock.

There have been few studies on the relationship between the number of aftershocks and the fault parameter of the main shock. Instead, time decay of aftershock occurrence has been extensively studied. The Omori formula, that the aftershock number per unit time decreases in the hyperbolic rate, was found by Omori (1894). The modified Omori formula:

$$
n(t) \mathrm{d} t=\frac{K}{(t+c)^{p}} \mathrm{~d} t
$$

was proposed by Utsu (1957) and has been widely used, where $t$ is the time elapsed since the occurrence of the main shock, $n(t) \mathrm{d} t$ is the number of aftershocks which occur in the time interval between $t$ and $t+\mathrm{d} t$ and $K, c$, and $p$ are constants. $K$ is dependent on the threshold magnitude of aftershock counted.

Recently, Singh and Suárez (1988) investigated the number of aftershocks for large shallow thrust earthquakes which occur along the circum-Pacific subduction zones. They assumed two scaling relations, i.e., $\log N=M_{w}+C_{1}$ and $\log N=1.5 M_{w}+C_{2}$ where $M_{w}$ is the moment magnitude, and $C_{1}$ and $C_{2}$ are constants. Based on these two relations they discussed lack or excess of aftershocks. They focused on the regional variation in the number of aftershocks in connection with the interaction between the oceanic and continental plates.

We show, at first, the relations between the seismic moment and the number of aftershocks. Second, the relations between the number of aftershocks and the fault area are described. Finally we propose a new formula which shows the average rate of aftershock occurrence as a function of the main-shock fault area, time elapsed since the main shock occurred, and the threshold magnitude.

\section{Data Set and Method}

Only aftershock sequences which occur in the Japan region will be treated in this study because of the regional variation of the aftershock number as suggested by Singh and Suárez (1988). All sequences are selected from the Seismological Bulletin of the Japan Meteorological Agency (JMA) from 1964 to 1987 according to the criteria described below.

Table 1 shows all the large shallow events selected as the main shocks used in this study. The magnitude threshold for the main shock is set to be 6.5 . The smaller the threshold magnitude is, the more events may be used in this study. However, the seismic moments of earthquakes with JMA magnitude less than 6.5 is generally unavailable. We only use events whose seismic moment is known.

We use only shallow earthquakes, because deep events are rarely accompanied by aftershocks. Events with focal depth of $60 \mathrm{~km}$ and shallower are used in this study. We 


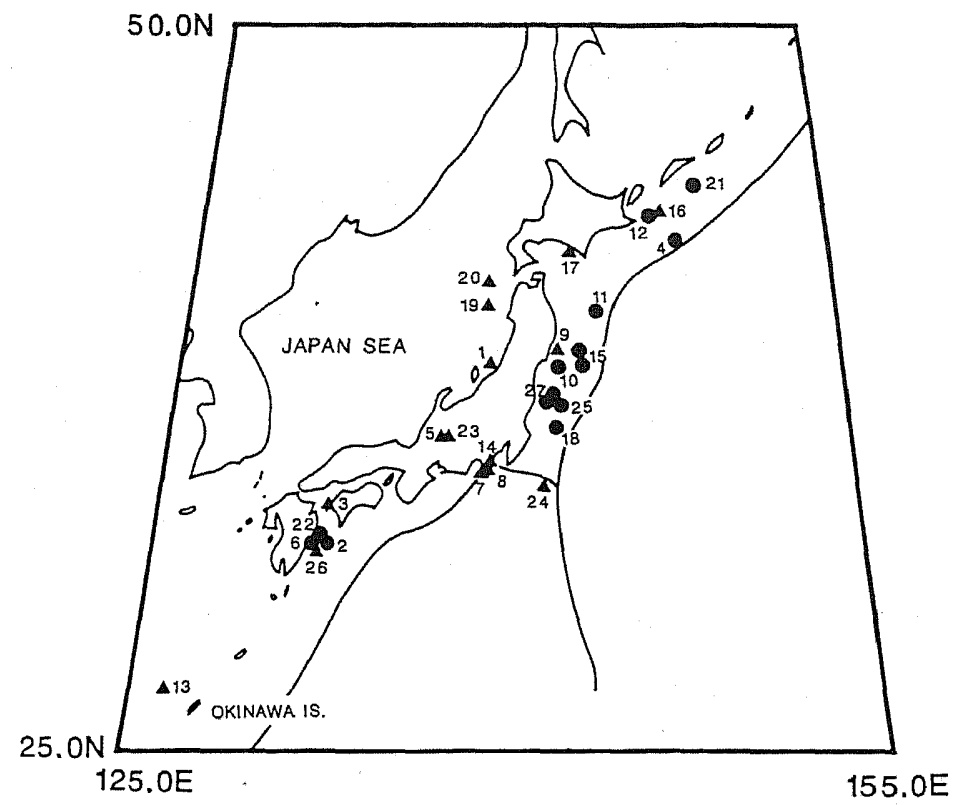

Fig. 1. The epicenters of main shocks used in this study. The solid circles represent interplate earthquakes and the triangles represent intraplate earthquakes. The numbers correspond to the event numbers in Table 1.

do not use the events before 1963, because the seismic moment of pre-WWSSN (World Wide Standardized Seismograph Network) events is often unavailable. Figure 1 shows the epicenters of the selected main shocks.

When the difference in magnitude between the largest event and the second largest is 0.6 or smaller, we regard the event as a doublet (Utsu, 1974). In the case of doublets, the sum of the seismic moments of the two events is used as the seismic moment of the main shock. Because of this procedure we cannot use aftershock sequences for which the seismic moment of the largest aftershock is unavailable, if the difference in magnitude between the main shock and the largest aftershock is 0.6 or smaller. Those include the 1968 Tokachi-Oki and the 1973 Nemuro-Oki earthquake sequences. This point will be discussed later in this paper.

Twenty-seven sequences are selected for this study. They are divided into two groups, interplate earthquakes (the solid circles in Fig. 1) and intraplate earthquakes (the solid triangles). Earthquakes which occur within the continental and the oceanic plates are both classified as intraplate events.

In most cases it is straightforward to distinguish the interplate and the intraplate events, but in some cases a few comments might be necessary to justify the classification and will be given in the following. For example, events 24 and 26 are classified as intraplate earthquakes because they are a normal fault earthquake (Seno, 1985; Fukushima et al., 1988). Event 9 is also classified as an intraplate earthquake because Seno et al. (1978) showed a fault plane solution consistent with the down-dip compression 
within the subducting slab. Events 1, 19, and 20, which occurred along the eastern margin of the Japan Sea, are treated as intraplate events. Although it has been suggested that the boundary between the North-American and Eurasian plates runs along the eastern margin of the Japan Sea (Nakamura, 1983; Mogi, 1985; Seno, 1983), the plate convergence of a small rate around $1 \mathrm{~cm} /$ year appears to be taken up within a broad belt-like (intraplate) region of the Japanese Islands.

We do not use a few large earthquakes that occurred in the margin of the JMA network, because those aftershocks may be too small to be located. Mochizuki et al. (1978) and Yokoyama (1984) showed that the magnitude threshold for detection near the margin of JMA network is larger than 4.5; all the aftershocks with magnitude 4.5 and above may not necessarily be listed in the JMA catalogue.

The event with magnitude 6.5 that occurred on July 26, 1986 near Okinawa Island, near the margin of JMA network, was accompanied by no reported aftershocks, and is not used in this study. Also event 13 occurred near Okinawa, but it is large enough (its magnitude is 6.7) to be accompanied by several aftershocks with JMA magnitude 4.5 and above.

We count the number of aftershocks which occur within a month after each main shock. If the constants $c$ and $p$ in the modified Omori formula, Eq. (1) are common in all the sequences, varying the time interval only causes an increase or decrease of the aftershock number by a constant ratio. According to Utsu (1969), the mean $p$-value in Eq. (1) is 1.3 and the mean $c$-value is 0.3 days. We set the time interval at one month. If it is too short, the aftershock number becomes too small. On the other hand, if it is too long, we may also count the events due to background activity. When an event is a doublet, we take one-month interval from the second event.

We count aftershocks within a calculated aftershock area to avoid background activity in the neighboring areas. This area, $A$, is calculated with the Utsu and Seki (1955) formula, $\log A=1.02 M-4$. We use the moment magnitude, $M_{w}$ for the magnitude $M$ in this formula because the JMA magnitude is underestimated for earthquakes with $M_{w} \geq 71 / 2$ (e.g., Utsu, 1982). Tajima and Kanamori (1985) suggested that the moment magnitude can be applied to the Utsu and Seki formula. We assumed a rectangular area with a ratio of length to width being 2:1 (see Fig. 2).

We set the threshold magnitude at 4.5 ; we only count the number of aftershocks with magnitude 4.5 and above. We plotted the cumulative number of aftershocks versus JMA magnitude for each sequence and assured that the threshold magnitude for detection is smaller than 4.5 in all cases. In the case of event 8 , no aftershocks with magnitude larger than 4.5 took place. We estimated the number of aftershocks, $N$, by fitting the Gutenberg and Richter relation, $\log N=a-b M$ to the observed magnitude frequency plot (see Fig. 3). The $b$-value is assumed to be 1.0 , and the number of aftershocks for this event is estimated to be 0.6. All the aftershock numbers thus counted are listed in Table 1.

When the threshold magnitude is larger than 4.5, we can also estimate the number of aftershocks with magnitude 4.5 and above by extrapolating the Gutenberg and Richter relation. But this would cause a serious error when the number of aftershocks is large, because the logarithmic scale is used. In the following analysis we do not use such a sequence. The 1978 Etorofu-Kinkai earthquake sequence is an example. This 


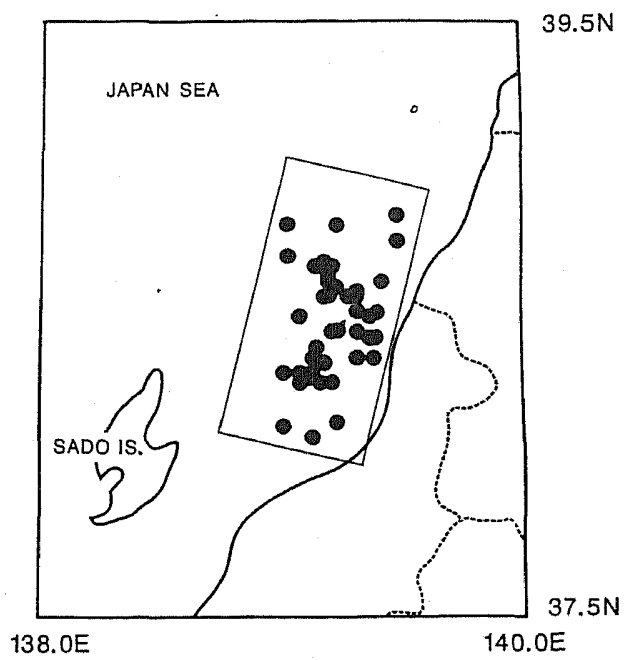

Fig. 2. The distribution of the aftershocks with magnitude 4.5 and above for event 1 . We count the number within the rectangular area with a ratio of length to width being $2: 1$. It is shown by the fine line.

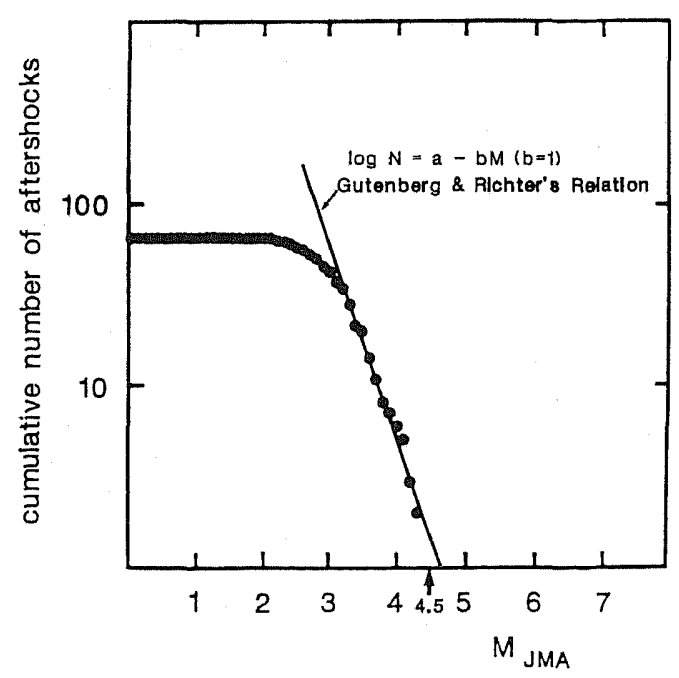

Fig. 3. The cumulative number $(N)$ of aftershocks with magnitude $M_{\mathrm{J}}$ and above which occurred within a month after event 8 . The line shows the Gutenberg and Richter relation, $\log N=a-b M$. Since for this event, no aftershocks with magnitude 4.5 and above were reported, we estimate the expected number of aftershocks with magnitude 4.5 and above using the above relation.

data will be examined later in this paper.

In the following we will use the weighted least-squares method to obtain empirical scaling relations. The variance in the logarithm of the aftershock number $N$ is obtained 
Table 1. The main shocks and their aftershock number.

\begin{tabular}{|c|c|c|c|c|c|c|c|c|c|c|}
\hline No. & & Date & & $M_{\mathrm{j}}^{* 2}$ & Dep. $* 2$ & $M_{0}^{* 2}$ & $N^{* 2}$ & Type*3 & Region & Ref.*4 \\
\hline 1 & 16 & June & 1964 & 7.5 & 40.0 & $3.2 \mathrm{E} 27$ & 43 & A & Niigata & $\mathrm{AB} 1$ \\
\hline 2 & 1 & Apr. & 1968 & 7.5 & 30.0 & $1.8 \mathrm{E} 27$ & 3 & E & Hyuganada & $\mathrm{SH}$ \\
\hline 3 & 6 & Aug. & 1968 & 6.6 & 40.0 & $2.1 \mathrm{E} 26$ & 4 & A & Bungosuido & SM \\
\hline 4 & 12 & Aug. & 1969 & 7.8 & 30.0 & $2.2 \mathrm{E} 28$ & 76 & E & Hokkaido-Toho-Oki & $\mathrm{AB} 2$ \\
\hline 5 & 9 & Sept. & 1969 & 6.6 & 0.0 & $3.5 \mathrm{E} 25$ & 6 & A & Gifu-Nagano & MI \\
\hline 6 & 26 & July & 1970 & 6.7 & 10.0 & $4.1 \mathrm{E} 26$ & 4 & $\mathrm{E}$ & Hyuganada & SH \\
\hline 7 & 9 & May & 1974 & 6.9 & 10.0 & $5.9 \mathrm{E} 25$ & I & $\mathrm{A}$ & Izu-Oki & $\mathrm{AB} 3$ \\
\hline 8 & 14 & Jan. & 1978 & 7.0 & 0.0 & $1.1 \mathrm{E} 26$ & 0.6 & A & Izu-Oshima & SS \\
\hline 9 & 20 & Feb. & 1978 & 6.7 & 50.0 & $7.0 \mathrm{E} 25$ & 5 & A & Miyagi-Oki & CMT \\
\hline 10 & 12 & June & 1978 & 7.4 & 40.0 & $3.4 \mathrm{E} 27$ & 9 & E & Miyagi-Oki & CMT \\
\hline 11 & 20 & Feb. & 1979 & 6.5 & 0.0 & $3.5 \mathrm{E} 25$ & 2 & $\mathrm{E}$ & Sanriku-Oki & CMT \\
\hline 12 & 23 & Feb. & 1980 & 6.8 & 30.0 & $5.6 \mathrm{E} 26$ & 8 & $\mathrm{E}$ & Kurile & CMT \\
\hline 13 & 3 & Mar. & 1980 & 6.7 & 20.0 & $3.4 \mathrm{E} 25$ & 7 & A & Okinawa & CMT \\
\hline 14 & 29 & June & 1980 & 6.7 & 10.0 & $4.1 \mathrm{E} 25$ & 4 & A & Izuoshima-Kinkai & CMT \\
\hline \multirow[t]{2}{*}{$15^{* 1}$} & 19 & Jan. & 1981 & 7.0 & 0.0 & $4.2 \mathrm{E} 26$ & 6 & $\mathrm{E}$ & Miyagi-Oki & CMT \\
\hline & 23 & Jan. & 1981 & 6.6 & 0.0 & & & & & CMT \\
\hline 16 & 3 & Sept. & 1981 & 6.5 & 30.0 & $7.5 \mathrm{E} 25$ & 1 & A & Kurile & CMT \\
\hline 17 & 21 & Mar. & 1982 & 7.1 & 40.0 & $2.6 \mathrm{E} 26$ & 18 & A & Urakawa-Oki & CMT \\
\hline 18 & 23 & July & 1982 & 7.0 & 30.0 & $3.9 \mathrm{E} 26$ & 9 & $\mathrm{E}$ & Ibaraki-Oki & CMT \\
\hline 19 & 26 & May & 1983 & 7.7 & 14.0 & $4.6 \mathrm{E} 27$ & 65 & A & Akita-Oki & CMT \\
\hline 20 & 21 & June & 1983 & 7.1 & 6.0 & $1.9 \mathrm{E} 26$ & 7 & A & Aomori-Oki & CMT \\
\hline 21 & 24 & Mar. & 1984 & 6.8 & 40.0 & $6.4 \mathrm{E} 26$ & 5 & E & Etorofu-Kinkai & CMT \\
\hline 22 & 7 & Aug. & 1984 & 7.1 & 33.0 & $2.9 \mathrm{E} 26$ & 1 & E & Miyazaki-Oki & CMT \\
\hline 23 & 14 & Sept. & 1984 & 6.8 & 2.0 & $2.6 \mathrm{E} 25$ & 10 & A & Gifu-Nagano & CMT \\
\hline 24 & 19 & Sept. & 1984 & 6.6 & 13.0 & $2.1 \mathrm{E} 26$ & 7 & A & Boso-Oki & CMT \\
\hline 25 & 6 & Feb. & 1987 & 6.7 & 35.0 & $1.3 \mathrm{E} 26$ & 1 & $\mathrm{E}$ & Fukushima-Oki & CMT \\
\hline 26 & 18 & Mar. & 1987 & 6.6 & 48.1 & $1.2 \mathrm{E} 26$ & 4 & A & Miyazaki-Oki & CMT \\
\hline \multirow[t]{2}{*}{$27^{* 1}$} & 7 & Apr. & 1987 & 6.6 & 44.0 & $2.2 \mathrm{E} 26$ & 4 & E & Fukushima-Oki & CMT \\
\hline & 23 & Apr. & 1987 & 6.6 & 46.8 & & & & & CMT \\
\hline
\end{tabular}

*1 Earthquake doublet. *2 $M_{\mathrm{J}}$, JMA magnitude; Dep, hypocentral depth in $\mathrm{km} ; M o$, seismic moment in dyne $\cdot \mathrm{cm} ; N$; observed number of aftershocks with JMA magnitude 4.5 and above, which occur within a month after the main shock. ${ }^{* 3} \mathrm{E}$ indicates interplate earthquakes, A indicates intraplate earthquakes. $* 4$ The references are: $\mathrm{AB} 1=\mathrm{Abe}, 1975 ; \mathrm{SH}=$ Shiono et al., 1980; $\mathrm{SM}=$ Shiono and Mikumo, 1975; $\mathrm{AB} 2=\mathrm{Abe}, \quad 1973 ; \mathrm{MI}=\mathrm{Mikumo}, 1973 ; \mathrm{AB} 3=\mathrm{Abe}, 1978 ; \mathrm{SS}=$ Shimazaki and Somerville, 1979; CMT = Dziewonski et al., $1983 \mathrm{a}, \mathrm{b}, 1984,1985,1987 \mathrm{a}, \mathrm{b}, 1988 \mathrm{a}, \mathrm{b}, \mathrm{c}, \mathrm{d}$.

as follows:

$$
\begin{aligned}
\operatorname{Var}[\log N] & =\left(\frac{\partial \log N}{\partial N}\right)^{2} \operatorname{Var}[N] \\
& =\frac{\operatorname{Var}[N]}{(N \ln 10)^{2}} \\
& =\frac{1}{N(\ln 10)^{2}} .
\end{aligned}
$$

Since aftershock sequence can be modeled as a non-stationary Poisson process (Lomnitz 
and Hax, 1966), we can assume that the variance of the aftershock number is equal to the number itself. Thus the variance of $\log N$ is proportional to an inverse of the number itself. Please note that the above weighting scheme has nothing to do with the accuracy of counting aftershock numbers. We assume that accuracy is independent of the aftershock number. The larger weight on the large number is a result of the combined effect of two factors. The first is that we are concerned with the logarithm of the number and not the number itself. Thus, not the standard deviation itself, but the deviation relative to the observed value becomes important. The second is the very nature of the Poisson process, namely that the variance $\sigma^{2}$ is equal to the mean frequency $\mu$. When the mean frequency of earthquake occurrence in a certain time interval is $\mu$, then we can expect to observe $\mu \pm \sigma$ shocks, i.e., $\mu \pm \sqrt{\mu}$, shocks in that time interval. Thus the relative deviation becomes $\sqrt{\mu} / \mu$, that is $1 / \sqrt{\mu}$, which is large when $\mu$ is small.

\section{Number of Aftershocks and the Seismic Moment of the Main Shock}

Figure 4 shows the relation between the logarithmic number of aftershocks and the logarithm of the seismic moment for all aftershock sequences listed in Table 1. Open circles are interplate earthquakes and solid circles are intraplate earthquakes. The figure suggests that the aftershock number for interplate earthquakes appears to be systematically smaller than that for intraplate earthquakes. The line in this figure was drawn based on an empirical approach and will be described in a later section.

Figures 5 and 6 show plots of $\log N$ versus $\log M_{o}$ for interplate and intraplate

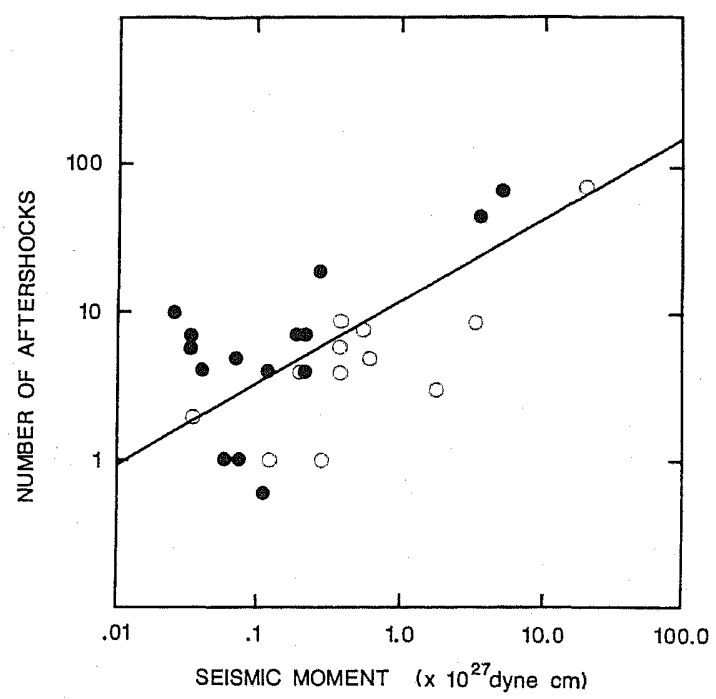

Fig. 4. A plot of logarithm of the number of aftershocks against that of seismic moment for all main shocks listed in Table 1. The open circles indicate the interplate earthquakes, the solid circles indicate the intraplate earthquakes. The straight line shows the relation, $\log N=2 / 3 b \log M_{o}-14.2$, where $b=0.85$, derived from the standard aftershock sequence proposed by Utsu (1969).

Vol. 38 , No. 4,1990 


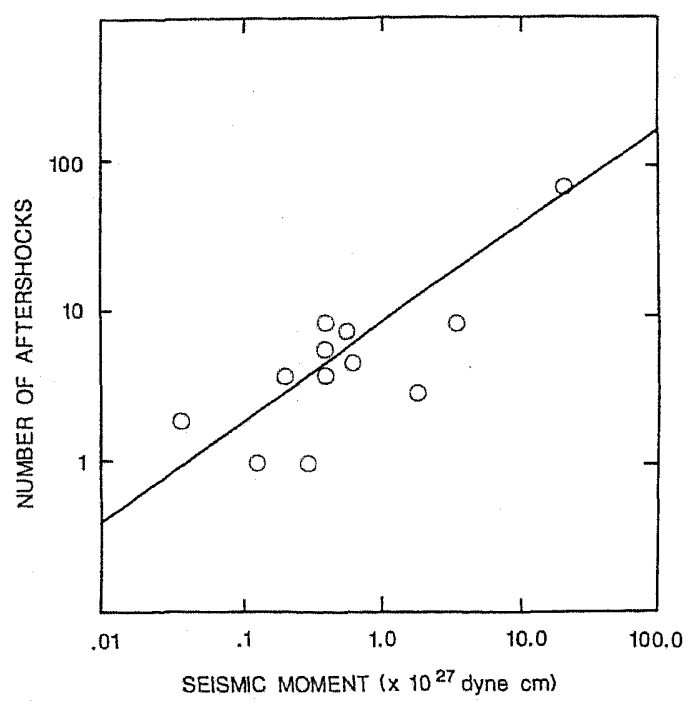

Fig. 5. A plot of logarithm of the number of aftershocks against that of seismic moment for interplate earthquakes. The best fit line with the slope of $2 / 3$ is shown in the figure.

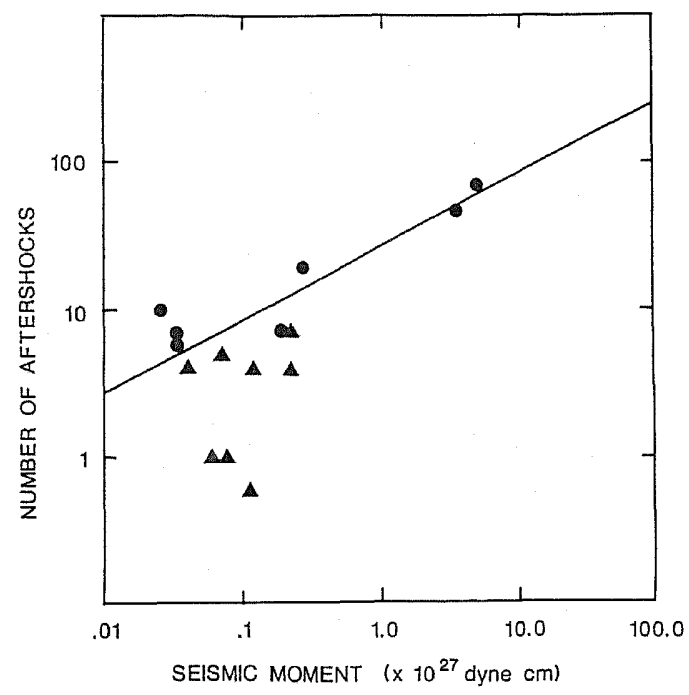

Fig. 6. A plot of logarithm of the number of aftershocks against that of seismic moment for intraplate earthquakes. The best fit line with the slope of $1 / 2$ is shown in the figure. The solid circles show intraplate earthquakes within the continental plate and the solid triangles those within the oceanic plate. A systematic difference between the two groups will be discussed in Discussion. 
earthquakes, respectively. We obtain the regression lines between the logarithm of number of aftershocks and the logarithm of seismic moment (in unit of dyne $\cdot \mathrm{cm}$ ) by the weighted least-squares method,

$$
\log N=0.66 \log M_{o}-16.86
$$

for interplate earthquakes, and

$$
\log N=0.51 \log M_{o}-11.54
$$

for intraplate earthquakes. For intraplate events, there are a few events well below the best fit line. Because of the small number of aftershocks, the weight of those events is very small. There appears to be a systematic difference between intraplate earthquakes within the continental plate (shown by the solid circles in Fig. 6) and those within the oceanic plate (the solid triangles). This point will be discussed later.

The obtained slopes are different for the two groups. We test whether the difference of the two slopes is significant. The $95 \%$ confidence intervals for the slopes are $0.66 \pm 0.044(0.62 \sim 0.70)$ for interplate earthquakes and $0.51 \pm 0.037(0.47 \sim 0.55)$ for intraplate earthquakes. This result indicates that the difference between the two groups is statistically significant.

The slope of the best fit line for interplate earthquakes is very close to $2 / 3$, and that for intraplate earthquakes is very close to $1 / 2$. Thus we attempt to obtain the relationships by fixing the slopes at $2 / 3$ and $1 / 2$ for interplate and intraplate earthquakes, respectively. The obtained relationships are:

$$
\log N=\frac{2}{3} \log M_{o}-17.05
$$

for interplate earthquakes, and

$$
\log N=\frac{1}{2} \log M_{o}-12.08
$$

for intraplate earthquakes.

\section{Scaling Relations}

The results of the previous sections show that the logarithmic number of aftershocks is scaled with the seismic moment of the main shock but it shows different slopes for inter- and intraplate Japanese earthquakes. In this section we will show first that a similar scaling difference can be observed between inter- and intraplate Japanese events in relationship of the fault area to the seismic moment. And finally it will be shown that the difference in the scaling of aftershock number reflects the difference in the scaling of fault area.

The scaling relation for a large earthquake between the fault area and the seismic moment is well known. Kanamori and Anderson (1975) showed that $\log M_{o} \sim 1.5 \log S$ holds for earthquakes with $M \geqq 6.0$. They also introduced similarities that the fault width and slip are suggested to be scaled with the fault length of a rectangular fault. 
Thus the scaling relation between the fault area and the seismic moment can be interpreted as $M_{o} \propto S^{3 / 2} \propto L^{3}$, where $L$ indicates the fault length, because the seismic moment $M_{o}$ is proportional to a product of the fault area and the slip.

On the other hand, Shimazaki (1986) proposed a scaling law, $M_{o} \propto L^{2}$ for large intraplate earthquakes in Japan. Because the fault width, $W$, for large intraplate event $\left(M_{o} \geqq 7.5 \times 10^{25}\right.$ dyne $\left.\cdot \mathrm{cm}\right)$ is bounded by the thickness of the seismogenic layer, the fault width is not scaled with the fault length. Thus only the slip is found to be proportional to the fault length and we obtain $M_{o} \propto L^{2}$.

We recalculate below the relations between the seismic moment (in unit of dyne $\cdot \mathrm{cm}$ ) and the fault surface area (in unit of $\mathrm{km}^{2}$ ) for inter- and intraplate earthquakes in Japan. For interplate earthquakes we obtain the following relationship using events whose source parameters are'known (see Fig. A1, Appendix).

$$
\log S=\frac{2}{3} \log M_{o}-14.87
$$

Sato (1979) obtained almost the same relationship using both inter- and intraplate earthquakes that Kanamori and Anderson (1975) compiled. If we introduce the geometrical similarity $L \propto W$ for interplate earthquakes, Eq. (6) can be interpreted as $M_{o} \propto S^{3 / 2} \propto L^{3}$.

For intraplate earthquakes, Shimazaki (1986) obtained the empirical relation between the fault length (in unit of $\mathrm{km}$ ) and the seismic moment of large intraplate event as follows:

$$
\log L=0.524 \log M_{o}-12.44 \quad \text { for } \quad M_{o} \geqq 7.5 \times 10^{25} \mathrm{dyne} \cdot \mathrm{cm} .
$$

The slope he obtained is nearly equal to 0.5 . Again we fix the slope to be 0.5 and obtain the following relationship (see Fig. 7),

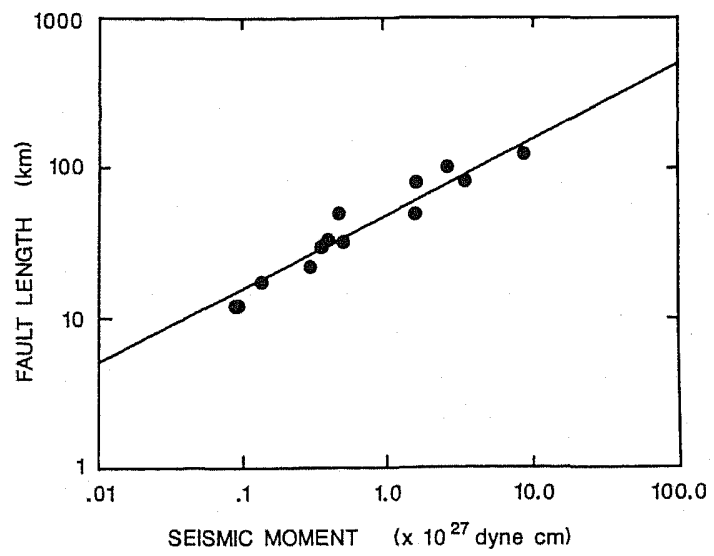

Fig. 7. A plot of logarithm of the fault length against that of seismic moment for the events whose moment is larger than $7.5 \times 10^{25} \mathrm{dyne} \cdot \mathrm{cm}$. We used the same data set which was used by Shimazaki (1986). The best fit line with the slope of $1 / 2$ is shown. 


$$
\log L=\frac{1}{2} \log M_{o}-11.79
$$

These results suggest that the seismic moment is proportional to a cube of the fault length for interplate earthquakes and to a square of the fault length for intraplate earthquakes.

Comparison of the above relations (6) and (7) with the relations (4) and (5), naturally leads us to conclude that the difference of the slope between the relations (4) and (5) reflect the difference of the scaling relations (6) and (7) between the interplate and intraplate earthquakes.

The relations (4) and (6) indicate that the logarithms of both the number of aftershocks and the fault area are in proportion to the logarithm of the seismic moment and the two proportional constants are the same, i.e., 2/3. Thus the number of aftershocks is in proportion to the fault area for interplate earthquakes. We obtain the following relationship from relations (4) and (6):

$$
\log N=\log S-2.18 \text {. }
$$

By using relations (5) and (7), we also obtain a similar result for intraplate earthquakes,

$$
\log N=\log L-0.29 \text {. }
$$

This relationship shows that for intraplate earthquakes the number of aftershocks is in proportion to the fault length. Since the fault length becomes proportional to the fault area when the fault width is limited by the thickness of the seismogenic layer, we rewrite Eq. (9) by using the fault width $W$ as follows:

$$
\log N=\log \frac{S}{W}-0.29=\log S-\log W-0.29 .
$$

The relation indicates that the number of aftershocks is proportional to the fault area also for intraplate earthquakes. The fault width for intraplate earthquakes is usually about $15-20 \mathrm{~km}$, but sometimes becomes as large as $30 \mathrm{~km}$ for dipping faults. By assuming that the fault width ranges from 15 to $30 \mathrm{~km}$, the above relation is rewritten as follows:

$$
\log N=\log S-(1.47 \sim 1.77) \text {. }
$$

\section{Areal Density of Aftershock Numbers}

We can calculate the average areal densities of aftershocks from the relationships between the aftershock number and the fault area obtained in the previous section for interplate and intraplate earthquakes.

For interplate earthquakes, the calculated areal density from relation (8) is $7.2 \times 10^{-3} / \mathrm{km}^{2}$. For intraplate earthquakes, we calculate the areal density from the obtained relationship (10) by assuming that the width of a fault is $15 \sim 30 \mathrm{~km}$. The areal density of intraplate earthquakes is estimated to be $3.4 \sim 1.7 \times 10^{-2} / \mathrm{km}^{2}$. Note that these densities refer to aftershocks which occur within a month after the main shock and with JMA magnitude 4.5 and above. The difference in the areal density between inter- and 
intraplate earthquakes will be discussed later.

\section{Empirical Approach}

In this section we will describe an empirical approach and will show a similar but different result obtained from our approach. It will help us to understand the basic difference between our new approach in this study and the conventional empirical one.

The straight line in Fig. 4 shows a relation obtained on the basis of the empirical formula as will be shown below. We assume that the number of aftershocks obeys the modified Omori's formula, Eq. (1). Utsu (1969) showed that the Gutenberg and Richter relationship holds for the aftershock sequence. He proposed the following formula for a 'standard' aftershock sequence; the number of aftershocks which occur $t$ days after the main shock is given as

$$
\begin{aligned}
n(t) \mathrm{d} t & =\frac{10^{b\left(M_{1}-M_{\mathrm{th}}\right)-a}}{(t+c)^{p}} \mathrm{~d} t \\
a & =1.83 ; \quad b=0.85 ; \\
c & =0.3 ; \quad p=1.3
\end{aligned}
$$

where $M_{1}$ is the magnitude of main shock and $M_{t h}$ is the threshold magnitude of the aftershocks. In Eq. (11), 0.85 shows the mean of the observed $b$-value of the Gutenberg-Richter relation for the aftershock sequence in Japan, 1.3 the mean of the observed $p$-value, and 0.3 the mean of the observed $c$-value (in days). From Eq. (11), the total number of aftershocks within $t$ days is represented by the following equation:

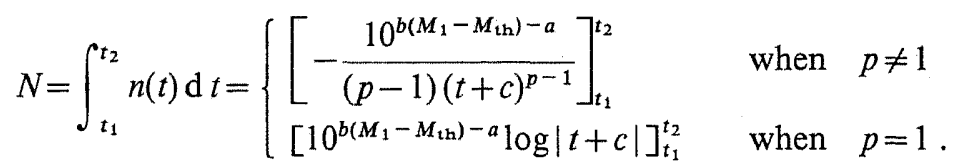

In this study the threshold magnitude is set at 4.5 and one-month time interval is used. By substituting these values into the above formula and by using the relation, $\log M_{o}=1.5 M_{1}+16.1$ (Kanamori, 1977), we obtain the relationship between the number of aftershocks and the seismic moment of the main shock. The relation obtained from conventional treatment of empirical formula by using the means of the observed $c$ - and $p$-values is

$$
\begin{aligned}
\log N & =\frac{2}{3} b \log M_{o}-17.06 b+0.55, \\
b & =0.85 .
\end{aligned}
$$

The above relation is shown in Fig. 4.

The proportional constant between the logarithmic aftershock number and the logarithm of the seismic moment is independent of the $c$ - and $p$-values, but dependent on the $b$-value. If there is a systematic difference between the $b$-values of aftershock sequence for interplate and intraplate earthquakes, we might be able to explain the observed difference in the proportional constants described in the previous section. 
However, any systematic difference of $b$-value was not found in Utsu (1969), who thoroughly investigated the $b$-value of aftershock sequences in Japan. We also attempt to estimate the $b$-values of the aftershock sequences used in this study. Errors in estimation are relatively large because of small number of samples and no systematic difference of $b$-values is found between inter- and intraplate earthquakes. Thus we can conclude that the difference of the slope is not caused by the difference in $b$-value.

\section{Aftershock Number for Standard Aftershock Sequence}

Utsu (1969) proposed Eq. (11) as a standard rate of occurrence of aftershocks per day. However, as shown in the previous section, Eq. (11) does not explain the difference between the inter- and intraplate earthquakes. In this section we propose a new formula for the occurrence rate of aftershocks.

In the previous section we showed that the number of aftershocks is proportional to the fault area. By assuming the Gutenberg-Richter relation and by using the modified Omori formula, our result leads us to propose:

$$
n(t) \mathrm{d} t=\frac{k S 10^{-b M_{\mathrm{th}}}}{(t+c)^{p}} \mathrm{~d} t,
$$

where $n(t)$ indicates the number of aftershocks which occur $t$ days after the main shock. $S$ indicates the fault area (in unit of $\mathrm{km}^{2}$ ), $M_{\mathrm{th}}$ is the threshold magnitude, $b, c$, and $p$ are the $b$-, $c$-, and $p$-values, respectively. The constant $k$ is different between inter- and intraplate earthquakes.

Setting the time interval at one month and threshold magnitude at 4.5 , and using $0.85,0.3$, and 1.3 as the $b$-, $c$-, and $p$-values, respectively, we obtain $k$-values as $k=13.44$ for interplate earthquakes, and $k=31.74 \sim 63.47$ for intraplate earthquakes.

\section{Discussion}

Yamashita and Knopoff (1987) showed that the Omori formula can be explained by the consequences of either of the two models of aftershock occurrence. In Model I they assume that some locked patches on a fault surface of the main shock produce aftershocks. These appear to represent "barriers," portions of the fault plane that remain unruptured (Das and Aki, 1977). In Model II, they assume that some small satellite faults surrounding the main-shock fault area produce aftershocks. If Model I holds and if the average areal density of locked patches is constant, the aftershock number becomes proportional to the main-shock fault area. On the other hand, if Model II holds and if the linear density of satellite faults along the edge of the main-shock fault is constant, the aftershock number becomes in proportion to the fault length. Our result is consistent with their Model I, because the aftershock number is proportional to the fault area of the main shock.

In our study we assume that there is no systematic local variation of aftershock number in the Japan region. According to Tsuboi et al. (1988), who examined a spatial variation in the number of aftershocks that occur in Japan, some local variation may be found. They suggested that it may be caused by the difference in the strength of 
coupling on the plate interface as was proposed by Singh and Suárez (1988).

Instead of local variation, it may be worthwhile to examine whether there exist any systematic difference in aftershock number between oceanic and continental intraplate earthquakes. Events $3,7,8,9,14,16,24$, and 26 are intraplate events which occur within the oceanic plates, i.e., the Pacific and the Philippine Sea plates. They are shown by the solid triangles in Fig. 6 while continental events are shown by the solid circles. A systematic difference between the two groups should be noted. Especially the numbers of aftershocks for three events (events 7, 8, and 16) are well below the fitted line in Fig. 6. Events 7 and 8 occurred within the Philippine Sea plate near the Izu Peninsula. It is also interesting to note that the aftershock number of the 1930 North-Izu earthquake, which took place within the Izu Peninsula on the Philippine Sea plate, is also very small. The seismic moment of this earthquake is $2.7 \times 10^{26}$ dyne $\cdot \mathrm{cm}$, and only 3 aftershocks with magnitude 4.5 and above occurred within one month after the main shock although 13.7 aftershocks are predicted from Eq. (5).

If we use only the continental intraplate events, we obtain by the weighted least-squares method,

$$
\log N=0.43 \log M_{o}-10.00
$$

instead of Eq. (3). The proportional constant is close to 0.5 and it is definitely different from that of the interplate event, i.e., 2/3. Thus our conclusions would not be changed if we only use the continental intraplate events. For the oceanic intraplate events, we cannot reliably derive any relationship because the seismic moments of all the events are smaller than $3 \times 10^{26}$ dyne $\cdot \mathrm{cm}$.

As was shown in the previous section, the areal density of aftershocks on the main-shock fault plane is higher for an intraplate earthquake than for an interplate earthquake. Further, it was suggested in this section that the areal density of a continental intraplate event may be systematically higher than that of an oceanic intraplate event. If the barriers, unbroken strong patches after an earthquake (Das and Aki, 1977; Mikumo and Miyatake, 1978) generate aftershocks, as was supported by Model I of Yamashita and Knopoff (1987), the above result indicates some intrinsic difference in rupturing process between intraplate and interplate earthquakes and also between continental and oceanic intraplate earthquakes. Continental intraplate earthquakes are suggested to be the most effective in the stress-roughening process (Aki, 1984). In other words, the above result suggests that the fault area is most heterogeneous after the occurrence of continental intraplate events.

Since the fault area is often determined from the aftershock distribution, one might argue that our result may be only a reflection of that the aftershock number is proportional to the aftershock area. Actually Seino (1984) and Ogata (1989) suggested that the number of aftershocks is in proportion to the aftershock area. However, if the fundamental physics lies in this proportionality, it would be difficult to explain why we obtain two different proportionality constants in the empirical relations between the logarithmic aftershock number and the logarithm of the seismic moment of the main shock.

One might argue that our results depend too much on a single event whose aftershock number is the largest, because of the weighting scheme introduced in the least-square 
fit. This argument appears valid for interplate events shown in Fig. 5, but is groundless for intraplate events. When the data excepting the largest event in each data set are used, we obtain the slope of 0.45 for intraplate earthquakes, which is close to $1 / 2$, but for interplate events the slope of 0.26 , far from $2 / 3$.

However, supporting evidence of the slope of $2 / 3$ for interplate events comes from the data set we discarded as less reliable. In Fig. 8, three data points which are not used in the above analysis are also plotted by the open triangles. These data points appear to fit well to the $2 / 3$ slope. Actually we obtain the least-square slope of 0.69 by using all events plotted in Fig. 8. Two of the three new points are the 1968 Tokachi-Oki (denoted by $\mathrm{T}$ in Fig. 8) and the 1973 Nemuro-Oki (N) sequences for which the seismic moment of the largest aftershock is unavailable while the difference in magnitude between the largest aftershock and the main shock is 0.6 or smaller. Instead of the sum of the moments of the main shock and the largest aftershock, the seismic moment of the main shock is used. Further, the threshold magnitude of these aftershocks appears to be slightly larger than 4.5. The third data point (E) represents the 1978 Etorofu-Kinkai earthquake sequence for which the threshold magnitude appears to be $4.8 \sim 5.1$. We did not try to extrapolate the Gutenberg and Richter relation, because it is too subjective. Thus we plot the observed aftershock number.

\section{Conclusion}

We investigate the relation between the number of aftershocks and the source parameters of the large earthquakes that occur in Japan. And we obtain the results as follows.

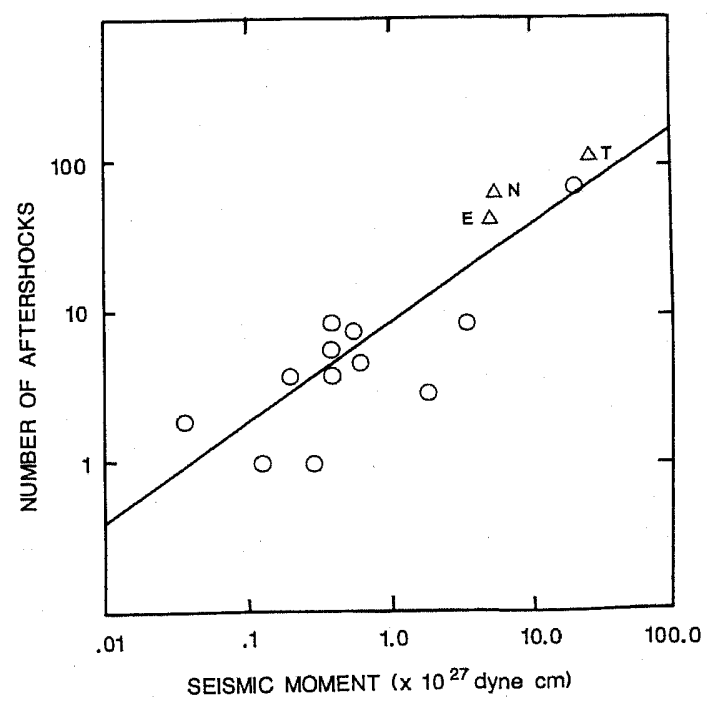

Fig. 8. Same as Fig. 5 except that three data points are added. They are shown by the open triangles: T, N, and E indicate the 1968 Tokachi-Oki, the 1973 Nemuro-Oki, and the 1978 Etorofu-Oki aftershock sequences, respectively.

Vol. 38 , No. 4, 1990 
The number of aftershocks with magnitude 4.5 and above which occur within a month after the main shock in Japan is proportional to the fault area, and is given as:

$$
N=7.2 \times 10^{-3} S \quad \text { for interplate earthquakes , }
$$

and

$$
N=1.7 \sim 3.4 \times 10^{-2} S \quad \text { for intraplate earthquakes . }
$$

The proportional relations are consistent with the hypothesis that aftershocks are generated by unbroken strong patches, or barriers on the main-shock fault, if the patch density is constant.

Reflecting the difference between the scaling relations for inter- and intraplate earthquakes, the relations between the aftershock number and the seismic moment are derived as

$$
\log N=\frac{2}{3} \log M_{o}-17.05
$$

for interplate earthquakes, and

$$
\log N=\frac{1}{2} \log M_{o}-12.08
$$

for intraplate earthquakes.

Further, we proposed the standard rate of aftershock occurrence, which is shown in Eq. (13).

The areal density of aftershocks on the main-shock fault for intraplate events is a few times as large as that for interplate events. This may indicate that the fault area after the main shock is more heterogeneous for intraplate earthquakes than that for interplate earthquakes. Further examination suggests that it may be slightly more heterogeneous for continental intraplate earthquakes than that for oceanic intraplate events.

We would like to thank Prof. T. Yamashita, who carefully read the manuscript and made valuable suggestions. We also wish to express our gratitude to Prof. K. Abe, Dr. T. Miyatake, and Dr. D. Weichert for their helpful comments on the manuscript.

\section{REFERENCES}

Abe, K., Tsunami and mechanism of great earthquakes, Phys. Earth Planet. Inter., 7, 143-153, 1973.

Abe, K., Re-examination of the fault model for the Niigata earthquake of 1964, J. Phys. Earth, 23, 349-366, 1975.

Abe, K., Dislocations, source dimensions and stresses associated with earthquakes in the Izu Peninsula, Japan, J. Phys. Earth, 26, 253-274, 1978.

Aki, K., Asperities, barriers, characteristic earthquakes and strong motion prediction, J. Geophys. Res., 89, 5867-5872, 1984. 
Das, S. and K. Aki, Fault plane with barriers: a versaltile earthquake model, J. Geophys. Res., 82, 5658-5670, 1977.

Dziewonski, A. M., J. E. Franzen, and J. H. Woodhouse, Centroid-moment tensor solutions for April-June 1983, January-March, July-September 1984, Phys. Earth Planet. Inter., 33, 243-249, 1983 a; 34, 209-219,1984; 38, 203-213, 1985.

Dziewonski, A. M., G. Ekstrom, J. E. Franzen, and J. H. Woodhouse, Global seismicity of 1978 , 1979, 1980, 1981, Phys. Earth Planet. Inter., 46, 316-342, 1987a; 48, 18-46, 1987b; 50, 127-154, 1988a; 50, 155-182, $1988 \mathrm{~b}$.

Dziewonski, A. M., G. Ekstrom, J. E. Franzen, and J. H. Woodhouse, Centroid-moment tensor solutions for January-March, April-June 1987, Phys. Earth Planet. Inter., 50, 116-126, 1988c; 215-225, $1988 \mathrm{~d}$.

Dziewonski, A. M., A. Friedman, D. Giardini, and J. H. Woodhouse, Global seismicity of 1982: Centroid-moment tensor solutions for 308 earthquakes, Phys. Earth Planet. Inter., 33, 76-90, 1983 b.

Fukushima, T., D. Suetsugu, and I. Nakanishi, Single station moment tensor inversion for near earthquakes, J. Phys. Earth, 36, 125-133, 1988.

Kanamori, H., The energy release in great earthquakes, J. Geophys. Res., 82, 2981-2987, 1977.

Kanamori, H. and D. L. Anderson, Theoretical basis of some empirical relations in seismology, Bull. Seismol. Soc. Am., 65, 1073-1095, 1975.

Lomnitz, C. and A. Hax, Clustering in aftershock sequences, Geophys. Monogr., 10, 502-508, 1966.

Mikumo, T., Faulting mechanism of the Gifu earthquake of September 9, 1969, and some related problems, J. Phys. Earth, 21, 191-212, 1973.

Mikumo, T. and T. Miyatake, Dynamical rupture process on a three-dimensional fault with non-uniform frictions and near-field seismic waves, Geophys. J. R. Astron. Soc., 54, 417-438, 1978.

Mochizuki, E., E. Kobayashi, and M. Kishio, Hypocenter determination ability of JMA seismological observation system during 1965-1974, Q. J. Seismol., 42, 23-30, 1978 (in Japanese).

Mogi, K., Tectonic singularities of the epicentral region of the 1983 Japan Sea earthquake, Zisin 2, 38, 262-265, 1985 (in Japanese).

Nakamura, K., The possibility of the new trench along the eastern margin of the Japan Sea, Bull. Earthq. Res. Inst., 58, 711-722, 1983 (in Japanese).

Ogata, Y., Statistical model for standard seismicity and detection of anomalies by residual analysis, Tectonophysics, 169, 159-174, 1989.

Omori, F., On the aftershocks of earthquake, J. Coll. Sci. Imp. Univ. Tokyo, 7, 111-200, 1894.

Sato, R., Theoretical basis on relationships between focal parameters and earthquake magnitude, J. Phys. Earth, 27, 353-372, 1979.

Sato, R., K. Abe, Y. Okada, K. Shimazaki, and Y. Suzuki, Handbook on Earthquake Fault Parameters of Japan, Kajima shuppankai, Tokyo, 390 pp., 1989 (in Japanese).

Seino, M., Statistical relations among magnitude, number and area of epicentral region, for earthquake clusters, Zisin 2, 37, 89-98, 1984 (in Japanese).

Seno, T., A consideration on the "Japan Sea subduction hypothesis" - Seismic slip vectors along the Japan Trench-, Zisin 2, 36, 270-273, 1983 (in Japanese).

Seno, T., The Boso-Oki earthquake $\left(M_{s}=6.7\right)$ of September 18,1984 and its tectonic implication, Programme and Abstract, Seismological Society of Japan, No. 1, 35, 1985 (in Japanese).

Seno, T., K. Ishibashi, and K. Sudo, The focal mechanism of the Miyagi-Oki earthquake of February 20, 1978, Programme and Abstract, Seismological Society of Japan, No. 1, 96,

Vol. 38 , No. 4, 1990 
1978 (in Japanese).

Shimazaki, K., Small and large earthquakes: the effects of the thickness of seismogenic layer and the free surface, in Earthquake Source Mechanics, Maurice Ewing Series 6, ed. S. Das, J. Boatwright, and C. H. Scholz, pp. 209-216, A.G.U., Washington, D.C., 1986.

Shimazaki, K. and P. Somerville, Static and dynamic parameters of the Izu-Oshima, Japan earthquake of January 14, 1978, Bull. Seismol. Soc. Am., 69, 1343-1378, 1979.

Shiono, K. and T. Mikumo, Tectonic implications of subcrustal, normal faulting earthquakes in the western Shikoku region, Japan, J. Phys. Earth, 23, 257-278, 1975.

Shiono, K., T. Mikumo, and Y. Ishikawa, Tectonics of the Kyusyu-Ryukyu arc as evidenced from seismicity and focal mechanism of shallow to intermediate-depth earthquakes, J. Phys. Earth, 28, 17-43, 1980.

Singh, S. K. and G. Suárez, Regional variation in the number of aftershocks $\left(m_{\mathrm{b}} \geqq 5\right)$ of large, subduction-zone earthquakes $\left(M_{w} \geqq 7.0\right)$, Bull. Seismol. Soc. Am., 78, 230-242, 1988.

Tajima, F. and H. Kanamori, Global survey of aftershock area expansion patterns, Phys. Earth Planet. Inter., 40, 77-134, 1985.

Tsuboi, Y., T. Unosawa, and T. Sato, The relation between short-period seismic motion and aftershock number, Programme and Abstract Seismological Society of Japan, No. 1, 23, 1988 (in Japanese).

Utsu, T., Magnitude of earthquakes and occurrence of their aftershocks, Zisin 2, 10, 35-45, 1957 (in Japanese).

Utsu, T., Aftershocks and earthquake statistics (I) Source parameters which characterize an aftershock sequence and their interrelations, J. Fac. Sci., Hokkaido Univ., Ser. VII, 3, 129-195, 1969.

Utsu, T., Space-time pattern of large earthquakes occurring off the Pacific Coast of the Japanese Islands, J. Phys. Earth, 22, 325-342, 1974.

Utsu, T., Relationships between earthquake magnitude scales, Bull. Earthq. Res. Inst., 57, 465-497, 1982 (in Japanese).

Utsu, T. and A. Seki, A relation between the area of after-shock region and the energy of main-shock, Zisin, 7, 233-240, 1955 (in Japanese).

Yamashita, T. and L. Knopoff, Models of aftershock occurrence, Geophys. J. R. Astron. Soc., 91, 13-26, 1987.

Yokoyama, H., Epicenter determination ability of the recent JMA network, Q. J. Seismol., 49, 53-65, 1984 (in Japanese). 


\section{APPENDIX}

We derive a scaling relation for a Japanese interplate event by using the data set listed in Table A1. The table shows all the Japanese interplate events whose source parameters are known (Sato et al., 1989). The fault area is calculated as a product of the fault length and width. If the event is a multiple shock, we use the sum of the fault area of all the subevents. Figure A1 shows the relation between the fault area and the seismic moment. The regression line is obtained by the least-squares method as

$$
\log S=0.67 \log M_{o}-14.96 \text {. }
$$

Table A1. Fault area and seismic moment of the Japanese interplate earthquakes.

\begin{tabular}{|c|c|c|c|c|c|}
\hline & Date & & $\begin{array}{l}\text { Fault area* } \\
\left(10^{3} \mathrm{~km}^{2}\right)\end{array}$ & $\begin{array}{l}\text { Seismic moment* } \\
\quad(\text { dyne } \cdot \mathrm{cm})\end{array}$ & Region \\
\hline 20 & Sept. & 1498 & 17.60 & $7.0 \mathrm{E} 28$ & (Meio) Tokai \\
\hline 30 & Feb. & 1605 & 31.00 & $1.2 \mathrm{E} 29$ & (Keicho) Tokai \\
\hline 2 & Dec. & 1611 & 12.25 & $6.9 \mathrm{E} 28$ & (Keicho) Sanriku \\
\hline 28 & Oct. & 1707 & 49.55 & $1.5 \mathrm{E} 29$ & (Hoei) Tokai, Nankaido \\
\hline 17 & Feb. & 1793 & 3.60 & $6.3 \mathrm{E} 27$ & (Kansei) Miyagi-Oki \\
\hline 23 & Dec. & 1854 & 23.05 & $4.6 \mathrm{E} 28$ & (Ansei) Tokai \\
\hline 24 & Dec. & 1854 & 28.50 & $8.1 \mathrm{E} 28$ & (Ansei) Nankaido \\
\hline 23 & Aug. & 1856 & 8.40 & 3.1E28 & (Ansei) Hachinohe-Oki \\
\hline 15 & June & 1896 & 10.50 & $5.9 \mathrm{E} 28$ & (Meiji) Sanriku \\
\hline 5 & Aug. & 1897 & 3.60 & $5.7 \mathrm{E} 27$ & (Meiji) Miyagi-Oki \\
\hline 1 & Sep. & 1923 & 4.46 & $8.0 \mathrm{E} 27$ & Kanto \\
\hline 9 & Mar. & 1931 & 3.00 & $1.0 \mathrm{E} 27$ & Hachinohe-Oki \\
\hline 11 & July & 1935 & 0.07 & $2.2 \mathrm{E} 25$ & Shizuoka \\
\hline 23 & May & 1938 & 3.00 & $4.0 \mathrm{E} 27$ & Shioya-Oki \\
\hline 5 & Nov. & 1938 & 6.00 & $7.0 \mathrm{E} 27$ & Shioya-Oki \\
\hline 5 & Nov. & 1938 & 6.00 & $4.8 \mathrm{E} 27$ & Shioya-Oki \\
\hline 6 & Nov. & 1938 & 3.83 & $3.8 \mathrm{E} 27$ & Shioya-Oki \\
\hline 7 & Nov. & 1938 & 4.28 & $3.2 \mathrm{E} 27$ & Shioya-Oki \\
\hline 4 & Mar. & 1952 & 13.00 & $2.6 \mathrm{E} 28$ & Tokachi-Oki \\
\hline 7 & Nov. & 1958 & 12.00 & $4.4 \mathrm{E} 28$ & Etorofu-Oki \\
\hline 12 & Aug. & 1961 & 1.00 & $4,2 \mathrm{E} 26$ & Kushiro-Oki \\
\hline 13 & Oct. & 1963 & 37.50 & $7.5 \mathrm{E} 28$ & Etorofu-Oki \\
\hline 17 & Mar. & 1965 & 0.18 & $5.0 \mathrm{E} 25$ & Aomori-Toho-Oki \\
\hline 29 & Mar. & 1965 & 0.15 & $5.5 \mathrm{E} 25$ & Aomori-Toho-Oki \\
\hline 1 & Apr. & 1968 & 1.79 & $1.8 \mathrm{E} 27$ & Hyuganada \\
\hline 23 & May & 1968 & 0.07 & $1.3 \mathrm{E} 25$ & Iwate-Oki \\
\hline 11 & Nov. & 1968 & 0.06 & $7.5 \mathrm{E} 24$ & Sanriku-Oki \\
\hline 12 & Aug. & 1969 & 15.30 & $2.2 \mathrm{E} 28$ & Hokkaido-Toho-Oki \\
\hline 28 & May & 1970 & 0.05 & $9.0 \mathrm{E} 24$ & Iwate-Oki \\
\hline 26 & July & 1970 & 0.74 & 4.1E26 & Hyuganada \\
\hline 17 & June & 1973 & 6.00 & $6.7 \mathrm{E} 27$ & Nemuro-Oki \\
\hline 12 & June & 1978 & 2.07 & $3.1 \mathrm{E} 27$ & Miyagi-Oki \\
\hline 23 & July & 1982 & 0.60 & $2.8 \mathrm{E} 26$ & Ibaraki-Oki \\
\hline
\end{tabular}

* All the data are taken from Sato et al. (1989).

Vol. 38, No. 4, 1990 


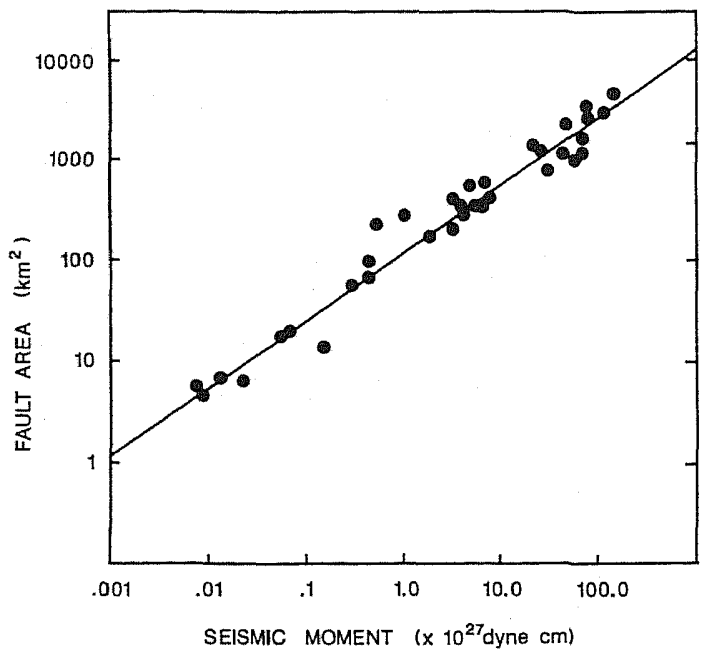

Fig. A1. A plot of logarithm of the fault area against that of the seismic moment for events listed in Table A1. The straight line shows the best fit line with the slope of $2 / 3$.

Since the slope of this regression line is close to $2 / 3$, we obtain the best fit line by fixing the slope at $2 / 3$ as

$$
\log S=\frac{2}{3} \log M_{o}-14.87
$$

and show it in Fig. A1. 